\title{
Case Report: Peptic ulcer disease following short-term use of \\ nonsteroidal anti-inflammatory drugs in a 3-year-old child
}

\section{[version 1; peer review: 2 approved with reservations]}

\author{
Alin Dumitru Ciubotaru, Carmen-Ecaterina Leferman (iD \\ Department of Pharmacology - Medical Specialties II, “Grigore T. Popa” University of Medicine and Pharmacy, Iasi, 700115, Romania
}

V1 First published: 22 May 2020, 9:419

https://doi.org/10.12688/f1000research.24007.1

Latest published: 09 Jun 2021, 9:419

https://doi.org/10.12688/f1000research.24007.2

\section{Abstract}

Background: Peptic ulcer disease (PUD) affects 1-2 per 1000 people annually in the USA, the UK and Europe, and occurs less frequently in children than in adults. PUD in children occurs mainly during the second decade of development. Among risk factors, nonsteroidal antiinflammatory drugs (NSAIDs), commonly used to manage acute febrile illness or pain in healthy children, is rarely reported to lead to PUD and upper gastrointestinal bleeding.

Case presentation: We present a rare case of upper gastrointestinal bleeding following a low dose ibuprofen treatment in a 3-year-old female. The patient with a family history of peptic ulcer was admitted for fever, coffee-ground vomiting and abdominal pain. The clinical examination revealed an altered general health status with a distended and mildly tender abdomen moving normally with respiration as well as normal stool. The initial laboratory test indicated anemia with reticulocytosis. During the first hours of hospitalization, the patient had a second episode of coffee-ground vomiting. An upper digestive endoscopy with biopsy was performed in the following six hours revealing a non-bleeding gastric ulcer at $2 \mathrm{~cm}$ from pylorus. Helicobacter pylori testing was negative. The patient was treated with a proton pump inhibitor (esomeprazole $10 \mathrm{mg} /$ day) for 2 months. There were no further gastrointestinal symptoms and hemoglobin values returned to normal, indicating resolution of her gastrointestinal bleeding.

Conclusion: The short-term utilization of NSAIDs in the appropriate dosage can lead to PUD, and considering the risk factors before administration can lead to an appropriate management.

\section{Keywords}

peptic ulcer disease, upper gastrointestinal bleeding, nonsteroidal anti-inflammatory drugs, proton pump inhibitors, children

\section{Open Peer Review}

Approval Status ? ?

1 2

version 2

(revision)

09 Jun 2021

version 1

22 May 2020

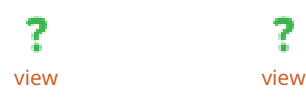

1. Parijat Ram Tripathi ID, Ankura Hospital for Women and Children, Hyderabad, India

2. Vera L. Sdepanian ${ }^{D}$, Universidade Federal de São Paulo, São Paulo, Brazil

Any reports and responses or comments on the article can be found at the end of the article. 
Corresponding authors: Alin Dumitru Ciubotaru (alin-dumitru-d-ciubotaru@d.umfiasi.ro), Carmen-Ecaterina Leferman (carmenecaterina-cd-leferman@d.umfiasi.ro)

Author roles: Ciubotaru AD: Conceptualization, Project Administration, Resources, Supervision, Writing - Original Draft Preparation;

Leferman CE: Conceptualization, Writing - Original Draft Preparation, Writing - Review \& Editing

Competing interests: No competing interests were disclosed.

Grant information: The author(s) declared that no grants were involved in supporting this work.

Copyright: $\odot 2020$ Ciubotaru AD and Leferman CE. This is an open access article distributed under the terms of the Creative Commons Attribution License, which permits unrestricted use, distribution, and reproduction in any medium, provided the original work is properly cited.

How to cite this article: Ciubotaru AD and Leferman CE. Case Report: Peptic ulcer disease following short-term use of nonsteroidal anti-inflammatory drugs in a 3-year-old child [version 1; peer review: 2 approved with reservations] F1000Research 2020, 9:419 https://doi.org/10.12688/f1000research.24007.1

First published: 22 May 2020, 9:419 https://doi.org/10.12688/f1000research.24007.1 


\section{Introduction}

Peptic ulcer disease (PUD) affects $1-2 / 1000$ people annually in the USA, UK and Europe and has been gradually decreasing ${ }^{1}$. An explanation could be the declining prevalence of Helicobacter pylori infection. While the rate of infections is decreasing, the rate of complications remains static, likely due to an aging population which has an elevated usage of ulcerogenic medication ${ }^{1}$

PUD occurs less frequently in children than adults. Epidemiological data are limited due to the rareness of the disease. An extensive study estimated the prevalence of ulcers and/or erosions in European children at $8.1 \%{ }^{2}$, occurring mainly during the second decade of development. In the USA, $17.4 \%$ of pediatric patients are diagnosed with upper gastrointestinal ulcers each year ${ }^{3}$.

PUD is a heterogenous disease defined by an imbalance between mucosa-protective and aggressive factors in the presence of risk factors including: $H$. pylori infection, chronic disease (inflammatory bowel disease, rheumatic diseases) and drug use, particularly nonsteroidal anti-inflammatory drugs (NSAIDs) ${ }^{2}$. In practice, NSAIDs are commonly used to manage acute febrile illness or pain in healthy children. One adverse reaction is acute gastrointestinal bleeding associated with short-term NSAIDs use, with a high rate of hospitalization and mortality in developed countries ${ }^{4}$. The adverse effect of short-term utilization of NSAIDs among children and their association with PUD are less clear.

We present a rare case of upper gastrointestinal bleeding following a low dose of ibuprofen in a 3-year-old to underline potentially severe side-effects of short-term NSAIDs use at appropriate doses in children.

\section{Case presentation}

A 3-year-old-female, with a family history of peptic ulcers, was admitted with fever, coffee-ground vomiting and abdominal pain. The mother stated the patient received two weightappropriate doses of ibuprofen and a dose of paracetamol, both administered within an appropriate time interval in the previous 24 hours for fever control. The patient had a positive medical history of upper respiratory tract infections with febrile seizures and interstitial pneumonia treated with antypiretics and clarithromycin, respectively. The patient is allergic to cephalosporin and Augmentin. No immune deficiency disease was documented.

Clinical examination revealed general malaise, pallor, fever, pharyngotonsillar congestion and productive cough, normal breath sound, a distended and mildly tender abdomen moving normally with respiration and normal stool. The patient weighed $15 \mathrm{Kg}$ and measured $88 \mathrm{~cm}$ tall.

Initial laboratory tests indicated anemia with reticulocytosis (Hematocrit 29.7\%, Hemoglobin 9.6 g/dl, reticulocytes 36/1000) and lower total protein $(55.2 \mathrm{~g} / \mathrm{L})$, characteristic of bleeding. Remaining laboratory results were normal, including coagulation tests.

Soon after hospitalization, the patient had a second episode of coffee-ground vomiting.

An upper digestive endoscopy with biopsy was performed revealing a non-bleeding gastric ulcer at $2 \mathrm{~cm}$ from pylorus (Figure 1). H. pylori testing was negative.

Based on this data, a diagnosis was made of NSAID-induced gastric ulcer, causing upper gastrointestinal bleeding.

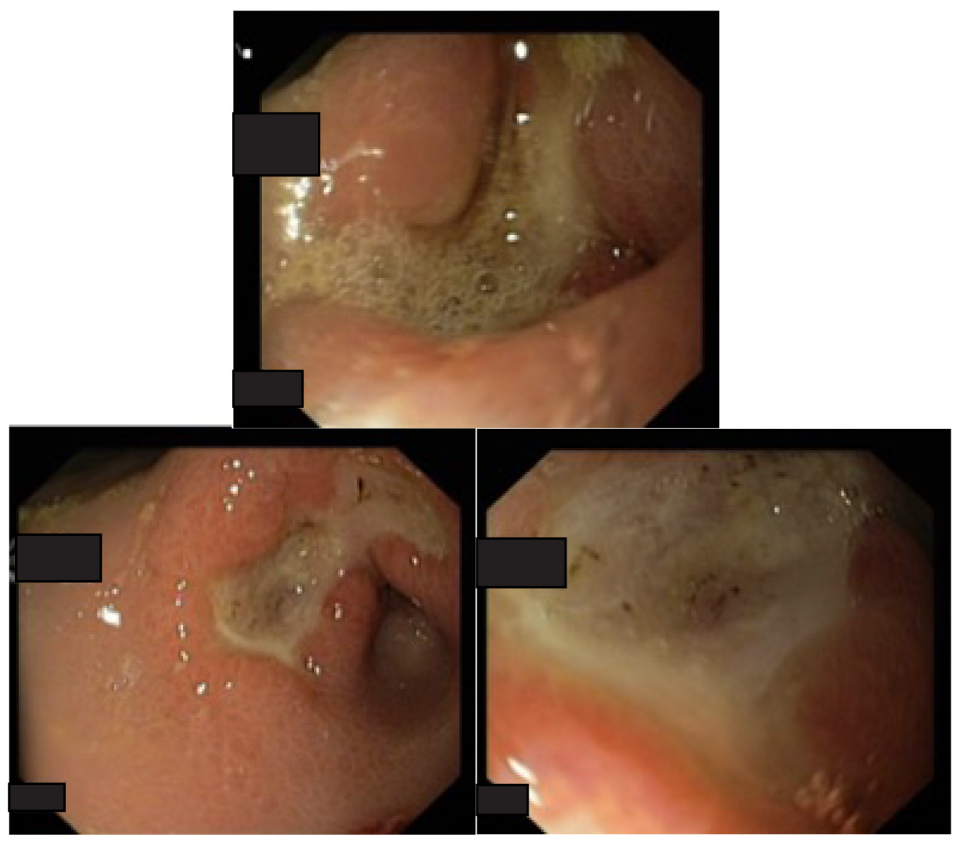

Figure 1. Endoscopic imaging. This shows a non-bleeding gastric ulceration measuring $2.5 \times 2 \mathrm{~cm}$ with edematous rim located $2 \mathrm{~cm}$ from the pyloric ring; pale gastric mucosa, fluid stasis and food debris; snake skin appearance of gastric mucosa in the fundus. 
During hospitalization, perfusion with glucose and electrolytes was administered in order to compensate for fluid loss. The patient was treated with a proton pump inhibitor (esomeprazole $10 \mathrm{mg} /$ day) for 2 months.

There were no further gastrointestinal symptoms. Hemoglobin values returned to normal, indicating resolution of gastrointestinal bleeding.

\section{Discussion}

Upper gastrointestinal bleeding in a 3-year-old following short-term NSAIDs use is an uncommon presentation. Similar cases $^{5}$ have been reported in literature, but the adverse effects of short-term NSAIDs use among children and their association with PUD is not completely understood. However, some studies offer compelling data indicating certain risk factors, primarily: the child's age ${ }^{2}$, NSAIDs consumption ${ }^{2,4,6,7}$ and H. pylori infection ${ }^{2,6-8}$.

PUD seems to primarily affect patients between 10-20 years $\mathrm{old}^{2}$. A retrospective cohort study reported a lower median age for those with gastric ulcers, than those with duodenal ulcers ${ }^{8}$. Our patient confirms this ratio.

The second important factor is NSAIDs consumption. The probability of PUD increases with the duration of therapy, dose and presence of risk factors, including positive familial history or drugs coadministration ${ }^{7,9}$. Thus, despite a low dose of ibuprofen, the gastric ulcer (GU) in this case can be explained in part by a positive family history and association with a dose of paracetamol. Moreover, some studies conclude that short-term NSAIDs use is highly correlated with $\mathrm{GU}^{6}$.

The association between short-term NSAIDs use and proton pump inhibitors (PPIs) can theoretically reduce the risk of upper gastrointestinal bleeding in children. Although coadministration of NSAIDs and PPIs is considered safe to reduce adverse gastrointestinal effects in adults ${ }^{10}$, there is not sufficient data about this drugs association in the prevention of short-term NSAIDs-PUDs in children.

The third important risk factor in PUD, H. pylori infection, was negative in our case. Some studies suggest a weaker association between $H$. pylori and PUD in children as compared with adults ${ }^{2,11}$. However, this infection is a well-recognized cause of chronic gastritis and plays an important role in the pathogenesis of PUD in children ${ }^{12}$.

Patients who develop gastrointestinal bleeding caused by NSAIDs-associated ulcers should discontinue use. Therapeutic strategies in these cases depend on the severity of presentation. Pharmacologic, endoscopic and surgical techniques have been developed to achieve hemostasis. In cases of massive bleeding, immediate endoscopic or surgical intervention is required. Scoring systems for upper gastrointestinal bleeding in children, laboratory tests and blood transfusion requirements are still under development ${ }^{13-15}$. In the present case, clinical presentation with two episodes of isolated hematemesis (coffee-ground vomiting) and endoscopic examination findings (non-bleeding gastric ulcer) correlated with laboratory tests indicated pharmacologic management.

\section{Conclusion}

Short term NSAIDs use in appropriate doses, commonly prescribed to control fever in children, can lead to PUD. Before administration, risk factors such as other antipyretic medication use, or a suggestive familial history must be considered. Doctors should inform caregivers of the risks involved and encouraging limited NSAIDs use.

\section{Data availability}

All data underlying the results are available as part of the article and no additional source data are required.

\section{Consent}

Written informed consent for the publication of this case report was obtained from the parents of the patient.
1. Sverdén E, Agréus L, Dunn JM, et al.: Peptic ulcer disease. BMJ. 2019; 367: 15495.

PubMed Abstract | Publisher Full Text

2. Kalach N, Bontems $P$, Koletzko $S$, et al.: Frequency and risk factors of gastric and duodenal ulcers or erosions in children: a prospective 1-month European multicenter study. Eur J Gastroenterol Hepatol. 2010; 22(10): 1174-1181. PubMed Abstract | Publisher Full Text

3. Brown $\mathrm{K}$, Lundborg $\mathrm{P}$, Levinson J, et al:: Incidence of peptic ulcer bleeding in the US pediatric population. J Pediatr Gastroenterol Nutr. 2012; 54(6): 733-736. PubMed Abstract | Publisher Full Text

4. Grimaldi-Bensouda L, Abenhaim L, Michaud L, et al.: Clinical features and risk factors for upper gastrointestinal bleeding in children: a case-crossover study. Eur J Clin Pharmacol. 2010; 66(8): 831-837. PubMed Abstract | Publisher Full Text

5. Berezin SH, Bostwick HE, Halata MS, et al:: Gastrointestinal bleeding in children following ingestion of low-dose ibuprofen. J Pediatr Gastroenterol Nutr. 2007;
44(4): 506-508.

PubMed Abstract | Publisher Full Text

6. Huang SC, Sheu BS, Lee SC, et al.: Etiology and treatment of childhood peptic ulcer disease in taiwan: a single center 9-year experience. $J$ Formos Med Assoc. 2010; 109(1): 75-81.

PubMed Abstract | Publisher Full Text

7. Cardile S, Martinelli M, Barabino A, et al.: Italian survey on non-steroidal anti-inflammatory drugs and gastrointestinal bleeding in children. World $\mathrm{J}$ Gastroenterol. 2016; 22(5): 1877-1883. PubMed Abstract | Publisher Full Text | Free Full Text

8. Roma E, Kafritsa Y, Panayiotou J, et al.: Is peptic ulcer a common cause of upper gastrointestinal symptoms? Eur J Pediatr. 2001; 160(8): 497-500. PubMed Abstract | Publisher Full Text

9. Autret-Leca E, Bensouda-Grimaldi L, Maurage C, et al.: Upper gastrointestinal complications associated with NSAIDs in children. Therapie. 2007; 62(2): 173-176.

PubMed Abstract | Publisher Full Text 
10. Gwee KA, Goh V, Lima G, et al.: Coprescribing proton-pump inhibitors with nonsteroidal anti-inflammatory drugs: risks versus benefits. J Pain Res. 2018; 11: $361-374$.

PubMed Abstract | Publisher Full Text | Free Full Text

11. Elitsur $Y$, Lawrence $Z$ : Non-Helicobacter pylori related duodenal ulcer disease in children. Helicobacter. 2001; 6(3): 239-243. PubMed Abstract | Publisher Full Text

12. Blecker U, Gold BD: Gastritis and peptic ulcer disease in childhood. Eur J Pediatr. 1999; 158(7): 541-546.

PubMed Abstract | Publisher Full Text

13. Nasher O, Devadason D, Stewart RJ: Upper Gastrointestinal Bleeding in
Children: A Tertiary United Kingdom Children's Hospital Experience. Children (Basel). 2017; 4(11): pii: E95

PubMed Abstract | Publisher Full Text | Free Full Text

14. Thomson MA, Leton N, Belsha D: Acute upper gastrointestinal bleeding in childhood: development of the Sheffield scoring system to predict need for endoscopic therapy. J Pediatr Gastroenterol Nutr. 2015; 60(5): 632-636. PubMed Abstract | Publisher Full Text

15. Garber A, Jang S: Novel Therapeutic Strategies in the Management of NonVariceal Upper Gastrointestinal Bleeding. Clin Endosc. 2016; 49(5): 421-424.

PubMed Abstract | Publisher Full Text | Free Full Text 


\title{
Open Peer Review
}

\section{Current Peer Review Status: ? ?}

\section{Version 1}

Reviewer Report 09 February 2021

https://doi.org/10.5256/f1000research.26483.r75841

(C) 2021 Sdepanian V. This is an open access peer review report distributed under the terms of the Creative Commons Attribution License, which permits unrestricted use, distribution, and reproduction in any medium, provided the original work is properly cited.

\author{
Vera L. Sdepanian \\ Division of Pediatric Gastroenterology, Department of Pediatrics, Escola Paulista de Medicina, \\ Universidade Federal de São Paulo, São Paulo, Brazil
}

This article is a case report of a 3-year-old-female that presented upper gastrointestinal bleeding, that the upper digestive endoscopy revealed a non-bleeding gastric ulcer at $2 \mathrm{~cm}$ from pylorus, and negative Helicobacter pylori testing. The patient received two weight-appropriate doses of ibuprofen and a paracetamol dose, both administered within an appropriate time interval in the previous 24 hours for fever control. Based on this data, the authors attributed the nonsteroidal anti-inflammatory drugs (NSAIDs) - ibuprofen - to the cause of the gastric ulcer.

1. In paragraph 3 of the Discussion section, the authors pointed out that positive family history of peptic ulcer and association with a dose of paracetamol could explain the gastric ulcer. First of all, the positive family history should be clarified, and secondly what should be the importance of using one dose of paracetamol.

2. The authors should emphasize all drugs used during at least in the last month because the patient "had a positive medical history of upper respiratory tract infections with febrile seizures and interstitial pneumonia treated with antipyretics and clarithromycin, respectively".

3. The patient was treated with a proton pump inhibitor (esomeprazole $10 \mathrm{mg} /$ day) for two months. Although there were no further gastrointestinal symptoms, and hemoglobin values returned to normal, there is no assurance that the ulcer improved. Therefore, the authors have to explain if another upper endoscopy was done and justify the reason do not perform it.

Is the background of the case's history and progression described in sufficient detail? Partly

Are enough details provided of any physical examination and diagnostic tests, treatment given and outcomes? 
Is sufficient discussion included of the importance of the findings and their relevance to future understanding of disease processes, diagnosis or treatment?

Partly

Is the case presented with sufficient detail to be useful for other practitioners?

Partly

Competing Interests: No competing interests were disclosed.

Reviewer Expertise: Pediatric Gastroenterologist

I confirm that I have read this submission and believe that I have an appropriate level of expertise to confirm that it is of an acceptable scientific standard, however I have significant reservations, as outlined above.

Author Response 31 May 2021

Carmen-Ecaterina Leferman, “Grigore T. Popa” University of Medicine and Pharmacy, Iasi, Romania

We would like to thank you for your time, for taking an interest in our article, and for your constructive feedback. All your concerns were valid, pointing out areas in which our case presentation needed improvement. We are therefore grateful for your valuable contribution. We will provide answers to each of your comments illustrating the changes point by point.

In paragraph 3 of the Discussion section, the authors pointed out that positive family history of peptic ulcer and association with a dose of paracetamol could explain the gastric ulcer. First of all, the positive family history should be clarified, and secondly what should be the importance of using one dose of paracetamol.

Thank you for your excellent point. As a result, we added in the text few lines in order to highlight this important consideration. The accumulation of more risk factors, like positive family history, NSAID administration or $\mathrm{H}$. Pylori infection in pediatric population affected by PUD, has been well documented. The father of the patient was diagnosed with PUD, but was unable to confirm whether he was $H$. Pylori positive. A joint effect of paracetamol (a dosage higher than $2 \mathrm{~g}$ ) combined with NSAIDs was reported in adults that had both compounds prescribed together. Conversely, the risk for GI ulcers and ulcer complications due to normal paracetamol intake has not been yet supported by available clinical data.

The authors should emphasize all drugs used during at least in the last month because the patient "had a positive medical history of upper respiratory tract infections with febrile seizures and interstitial pneumonia treated with antipyretics and clarithromycin, respectively".

Thank you for your suggestion. The mother declared that beside what we already mentioned, in the last month no other antipyretic medication was administered. In the first 
days of the upper respiratory infection ( 5 weeks prior to the bleeding episode) Ibuprofen $100 \mathrm{mg}$ every 8 hours for three days was administered, and the next two days when needed (two doses a day at an eight-hour interval). For the convulsion episode no antiseizure medication was needed. Also, clarithromycin $7.5 \mathrm{mg} / \mathrm{kg} /$ day was administered 10 days.

The patient was treated with a proton pump inhibitor (esomeprazole $10 \mathrm{mg} / \mathrm{day}$ ) for two months. Although there were no further gastrointestinal symptoms, and hemoglobin values returned to normal, there is no assurance that the ulcer improved. Therefore, the authors have to explain if another upper endoscopy was done and justify the reason do not perform it.

Follow-up upper GI endoscopy is mandatory in the case of complicated duodenal ulcers. The report of the endoscopy performed at the end of the treatment period confirmed the healing of the gastric ulceration area. We did not have access to the images.

Competing Interests: No competing interests were disclosed.

Reviewer Report 01 December 2020

https://doi.org/10.5256/f1000research.26483.r75153

(C) 2020 Tripathi P. This is an open access peer review report distributed under the terms of the Creative Commons Attribution License, which permits unrestricted use, distribution, and reproduction in any medium, provided the original work is properly cited.

\section{Parijat Ram Tripathi}

Ankura Hospital for Women and Children, Hyderabad, Telangana, India

Authors have emphasized the possibility of the development of gastric ulcers even on short and adequate doses of NSAIDs. The case report needs more information and clarity regarding certain aspects of predisposing factors, diagnostic tests, treatment, and follow-up.

There are multiple major and minor concerns which are mentioned below point by point:

\section{Major concerns:}

1. In the introduction, the second paragraph, "An extensive study estimated the prevalence of ulcers and/or erosions in European children at $8.1 \%$, occurring mainly during the second decade of development. In the USA, $17.4 \%$ of pediatric patients are diagnosed with upper gastrointestinal ulcers each year."

In both the studies endoscopies were performed for specific indications rather than in the general pediatric population. Please mention the indications for better clarity of information.

2. What were the hemodynamic parameters of the patient at admission? 
3. What tests were performed for $\mathrm{H}$. pylori in the patient?

4. Please give details of family history of peptic ulcer disease (PUD) and how was it diagnosed? Was that person $H$. pylori-positive?

5. In the discussion, the second paragraph, "A retrospective cohort study reported a lower median age for those with gastric ulcers, than those with duodenal ulcers. Our patient confirms this ratio." This is not right to say that this case report confirms this ratio. Please change or remove it.

6. How do authors think that the presence of positive family history (in absence of $H$. pylori) and paracetamol intake can explain the presence of gastric ulcer even with a low dose of NSAID? Please explain in more detail.

7. Why a repeat endoscopy was not performed to confirm the healing of gastric ulcer?

\section{Minor concerns:}

1. Please mention doses (in per $\mathrm{kg}$ ) and interval of ibuprofen used in the patient.

2. Please do not write the brand name until significant or important (e.g. Augmentin).

3. Duration and severity of respiratory tract infection are not mentioned. Please give details.

4. The patient's weight and height interpretation should be mentioned as per Z score.

5. Mention corrected reticulocyte count.

6. How laboratory reports (hemoglobin, hematocrit, total protein, and reticulocyte count) are suggesting bleeding characteristics? Please explain.

7. Please mention the dose of esomeprazole in $\mathrm{mg} / \mathrm{kg} /$ day along with the dose written in case details.

Is the background of the case's history and progression described in sufficient detail? Partly

Are enough details provided of any physical examination and diagnostic tests, treatment given and outcomes?

Partly

Is sufficient discussion included of the importance of the findings and their relevance to future understanding of disease processes, diagnosis or treatment?

Partly

Is the case presented with sufficient detail to be useful for other practitioners? 
Partly

Competing Interests: No competing interests were disclosed.

Reviewer Expertise: Pediatric gastroenterology and hepatology

I confirm that I have read this submission and believe that I have an appropriate level of expertise to confirm that it is of an acceptable scientific standard, however I have significant reservations, as outlined above.

Author Response 31 May 2021

Carmen-Ecaterina Leferman, “Grigore T. Popa” University of Medicine and Pharmacy, Iasi, Romania

We are appreciative of the opportunity and your support in improving upon the initial article. We have carefully followed your recommendations and made the necessary improvements, including relevant information regarding drugs administration, family history, medical history and nutritional status of the patient. Also, we elaborate more about the risk factors of peptic ulcer disease (PUD) in the discussion section.

In the introduction, the second paragraph, "An extensive study estimated the prevalence of ulcers and/or erosions in European children at $8.1 \%$, occurring mainly during the second decade of development. In the USA, $17.4 \%$ of pediatric patients are diagnosed with upper gastrointestinal ulcers each year."

In both the studies endoscopies were performed for specific indications rather than in the general pediatric population. Please mention the indications for better clarity of information.

Thank you for your observation. Regarding clarity of information related to epidemiology, we elaborated more about the indications for endoscopies mentioned in the two studies to which we referred in the second paragraph of the first version.

What were the hemodynamic parameters of the patient at admission?

We added the hemodynamic parameters of the patient at admission (Case presentation, first paragraph, first sentence).

What tests were performed for $H$. pylori in the patient?

A biopsy was performed during the initial upper endoscopy and the results were negative for H. pylori (Case presentation, fifth paragraph, last sentence).

Please give details of family history of peptic ulcer disease (PUD) and how was it diagnosed? Was that person $H$. pylori positive?

The father of the patient was diagnosed with PUD, but was unable to confirm whether he was H. Pylori positive.

In the discussion, the second paragraph, "A retrospective cohort study reported a lower median age for those with gastric ulcers, than those with duodenal ulcers. Our patient confirms this ratio." This is not right to say that this case report confirms this ratio. Please change or remove it.

We removed the sentence.

How do authors think that the presence of positive family history in absence of $H$. 
pylori) and paracetamol intake can explain the presence of gastric ulcer even with a

low dose of NSAID? Please explain in more detail.

Thank you for your excellent point. As a result, we added in the text few lines in order to highlight this important consideration. The accumulation of more risk factors, like positive family history, NSAID administration or $\mathrm{H}$. Pylori infection in pediatric population affected by PUD, has been well documented. A joint effect of paracetamol (a dosage higher than $2 \mathrm{~g}$ ) combined with NSAIDs was reported in adults that had both compounds prescribed together. Conversely, the risk for GI ulcers and ulcer complications due to normal paracetamol intake has not been yet supported by available clinical data.

Why a repeat endoscopy was not performed to confirm the healing of gastric ulcer? Follow-up upper GI endoscopy is mandatory in the case of complicated duodenal ulcers. The report of the endoscopy performed at the end of the treatment period confirmed the healing of the gastric ulceration area. We did not have access to the images.

Please mention doses (in per $\mathrm{kg}$ ) and interval of ibuprofen used in the patient. Two doses of $100 \mathrm{mg}-6,66 \mathrm{mg} / \mathrm{kg}$ - Ibuprofen by mouth, 8 hours apart.

Please do not write the brand name until significant or important (e.g. Augmentin). We replaced the brand name with amoxicillin/clavulanic acid.

Duration and severity of respiratory tract infection are not mentioned. Please give details.

The patient had a positive medical history of upper respiratory tract infections with febrile seizures and interstitial pneumonia treated with antipyretics and clarithromycin, respectively. The duration of the symptoms was 2 weeks, three weeks prior to the GI bleeding episode. We added this information in the new version.

The patient's weight and height interpretation should be mentioned as per $Z$ score.

The 3 year-old patient weighed $15 \mathrm{Kg}$ (z-score 0.65 ) and measured $88 \mathrm{~cm}$ tall (z-score -1.63 ) . She is at the 5 th percentile for stature, 72 nd percentile for weight. She has a body mass index (BMI) of 19.4 (z-score 2.15), placing the BMI-for-age at the $98^{\text {th }}$ percentile. (Case presentation, fourth paragraph, last sentence).

Mention corrected reticulocyte count.

We mentioned corrected reticulocyte count in the new version (Case presentation, fifth paragraph).

How laboratory reports (hemoglobin, hematocrit, total protein, and reticulocyte count) are suggesting bleeding characteristics? Please explain.

As mentioned in the text, lower values of hemoglobin $(9.6 \mathrm{~g} / \mathrm{dl})$ and hematocrit $(29.7 \%)$ suggest anemia, a potential sign of hemorrhage. In order to differentiate between different possible causes of anemia in children, additional parameters like reticulocyte count and protein levels were evaluated, identifying the reticulocytosis (corrected reticulocyte count of 3.24) and the hypoproteinemia ( $5.52 \mathrm{~g} / \mathrm{dL}$ ). Reticulocytosis is a compensatory mechanism of the bone marrow to increase production in order to compensate the red blood cell loss. Hypoproteinemia is associated with blood loss.

Please mention the dose of esomeprazole in $\mathrm{mg} / \mathrm{kg} /$ day along with the dose written in case details. 
The esomeprazole dosage was $10 \mathrm{mg} /$ day $(0.66 \mathrm{mg} / \mathrm{kg} /$ day). (Case presentation, ninth paragraph)

Competing Interests: No competing interests were disclosed.

The benefits of publishing with F1000Research:

- Your article is published within days, with no editorial bias

- You can publish traditional articles, null/negative results, case reports, data notes and more

- The peer review process is transparent and collaborative

- Your article is indexed in PubMed after passing peer review

- Dedicated customer support at every stage

For pre-submission enquiries, contact research@f1000.com 